\title{
Lysophosphatidylcholine, a Component of Atherogenic Lipoproteins, Induces Mononuclear Leukocyte Adhesion Molecules in Cultured Human and Rabbit Arterial Endothelial Cells
}

Noriaki Kume, Myron I. Cybulsky, and Michael A. Gimbrone, Jr.

Vascular Research Division, Departments of Pathology, Brigham and Women's Hospital and Harvard Medical School, Boston, Massachusetts 02115

\begin{abstract}
Accumulation of monocyte-derived foam cells in focal areas of the arterial intima is one of the key events in early atherogenesis. We have examined the effect of lysophosphatidylcholine (lyso-PC; lysolecithin), a major phospholipid component of atherogenic lipoproteins, on the expression of adhesion molecules for monocytes, such as vascular cell adhesion molecule-1 (VCAM-1) and intercellular adhesion molecule-1 (ICAM-1), in cultured human and rabbit arterial endothelial cells. Cultured rabbit aortic endothelial cells treated with lyso-PC showed increased mRNA and cell surface expression of VCAM-1 and ICAM-1, which was associated with increased adhesion of monocytes and monocyte-like cells (THP-1, U937). In cultured human iliac artery endothelial cells, lysoPC similarly induced both VCAM-1 and ICAM-1, whereas in umbilical vein endothelial cells only ICAM-1 was up-regulated. In all endothelial cells examined, the effect of lyso-PC on E-selectin (endothelial-leukocyte adhesion molecule-1) expression was negligible, thus differentiating this stimulus from other endothelial activators, such as interleukin 1, tumor necrosis factor, or lipopolysaccharide. We conclude that lyso-PC can selectively induce VCAM-1 and ICAM-1 in arterial endothelial cells and that this action, in addition to its monocyte chemoattractant activity, may play an important role in monocyte recruitment into atherosclerotic lesions. (J. Clin. Invest. 1992. 90:1138-1144.) Key word: atherosclerosis $\bullet$ intercellular adhesion molecule-1 - inflammation • oxidized low density lipoprotein $\bullet$ vascular cell adhesion molecule-1
\end{abstract}

\section{Introduction}

One of the critical events in the pathogenesis of atherosclerotic lesions is the focal accumulation of lipid-laden foam cells beneath an intact arterial endothelial lining (1-3). In various

These studies were presented at the 1991 Annual Meeting of the Federation of American Societies for Experiment Biology, Atlanta, GA, 2125 April 1991 and have appeared in abstract form (1991. FASEB J. 5:A1438).

Address reprint requests to Dr. Gimbrone, Vascular Research Division, Department of Pathology, Brigham \& Women's Hospital, 221 Longwood Avenue, LMRC-4, Boston, MA 02115.

Received for publication 4 April 1992.

J. Clin. Invest.

(C) The American Society for Clinical Investigation, Inc.

0021-9738/92/09/1138/07 \$2.00

Volume 90, September 1992, 1138-1144 cholesterol-fed animal models of atherosclerosis, localized attachment of circulating monocytes to arterial endothelium appears to precede the formation of early foam cell lesions (1-6). Although the molecular mechanisms are not completely understood, monocyte recruitment into these early lesions may involve changes in endothelial adhesiveness for monocytes, and local generation of soluble vessel wall-derived monocyte chemoattractants (7-9). In vitro studies have identified three molecules, intercellular adhesion molecule-1 (ICAM$\left.1^{1}[\mathrm{CD} 54]\right)(10,11)$, E-selectin (endothelial-leukocyte adhesion molecule-1 [ELAM-1]) $(12,13)$, and vascular cell adhesion molecule-1 (VCAM-1) (14), that are inducible on the endothelial surface and can support the adhesion of various leukocytes, including monocytes $(15,16)$. Our laboratory has recently demonstrated that VCAM-1 is inducible in activated rabbit aortic endothelial cells in culture, and also is focally expressed in vivo in arterial endothelium overlying early foam cell lesions in both dietary and genetic models of atherosclerosis in the rabbit (17). Immunohistochemical examination of aortas from cholesterol-fed rabbits indicates that VCAM-1 can be detected in arterial endothelium before the accumulation of intimal macrophages, suggesting that this molecule may play a role in the recruitment of blood monocytes into early lesions (18). Recent studies by others have shown that ICAM-1 also is expressed in human atherosclerotic lesions in vivo (19). However, the stimuli present in developing atherosclerotic lesions that might be responsible for focal up-regulation of VCAM-1, ICAM-1, and other potentially relevant leukocyte adhesion molecules have not been defined.

Several lines of evidence have indicated that oxidatively modified low density lipoproteins (LDL) play a key role in atherogenesis $(3,20-23)$. In cholesterol-fed rabbit models of atherosclerosis, the major increased lipoprotein fraction is $\beta$ VLDL (3). One of the characteristic features of both oxidized LDL and $\beta$-VLDL particles is their dramatically increased content of lysophosphatidylcholine (lyso-PC) (3, 20, 24-27). Lyso-PC has been demonstrated to be a selective chemoattractant for mononuclear leukocytes (24), and appears to be the component of oxidized LDL responsible for its inhibitory effect on endothelial-dependent vasodilation $(25,26)$. Furthermore, the concentration of lyso-PC is increased in atherosclerotic arterial lesions in animals fed an atherosclerotic diet (28).

1. Abbreviations used in this paper: ELAM-1, endothelial-leukocyte adhesion molecule-1; ICAM-1, intercellular adhesion molecule-1; lyso-PC, lysophosphatidylcholine (lysolecithin); VCAM-1, vascular cell adhesion molecule-1. 
Here, we demonstrate that lyso-PC selectively induces increased cell surface expression of VCAM-1 and ICAM-1 in cultured rabbit and human arterial endothelial cells, and that this is associated with enhanced mononuclear leukocyte adhesion.

\section{Methods}

Reagents. Lyso-PC (palmitoyl), lysophosphatidylethanolamine (palmitoyl), lysophosphatidylinositol (palmitoyl), phosphatidylcholine (dipalmitoyl), and lysophosphatidylserine (rat brain) were purchased from Avanti Polar Lipids (Alabaster, AL) or Calbiochem-Behring Corp. (La Jolla, CA). Lyso-PC analogues, 1-palmityl-propanediol-3phosphocholine and 1-palmitoyl-ethanediol-2-phosphocholine, were generous gifts from Dr. Sampath Parthasarathy (University of California at San Diego, La Jolla, CA). Recombinant human IL-1 $\beta$ was obtained from Biogen, Inc. (Cambridge, MA). LPS (Escherichia coli, 055:B5) and heparin (porcine intestinal) were purchased from Sigma Chemical Co. (St. Louis, MO); FITC-conjugated goat anti-mouse IgG $\mathrm{F}\left(\mathrm{ab}^{\prime}\right)_{2}$ fragments from Caltag Laboratories (South San Francisco, CA); 2',7'-bis-(2-carboxyethyl)-5-(and-6) carboxyfluorescein (BCECF) from Molecular Probes Inc. (Eugene, OR); Medium 199 (with $25 \mathrm{mM}$ Hepes, formula 89-0100PJ) and fetal bovine serum (FBS) from Gibco Laboratories (Gaithersburg, MD); endothelial cell growth supplement from Collaborative Research (Bedford, MA); and RPMI 1640 (with $25 \mathrm{mM}$ Hepes) from Whittaker Bioproducts (Walkersville, MD). All other chemicals were of reagent grade.

Cells. Rabbit aortic endothelial cells were isolated by collagenase digestion from thoracic aortas from male New Zealand White rabbits (Pasturella-free, 3-4 kg, Millbrook Farms, Amherst, MA), seeded in plastic plates (Costar, Cambridge, MA) precoated with $0.1 \%$ gelatin (Difco Laboratories, Detroit, MI) and cultured in Medium 199 supplemented with $20 \%$ fetal bovine serum (FBS), $12.5 \mu \mathrm{g} / \mathrm{ml}$ endothelial cell growth supplement, $25 \mathrm{U} / \mathrm{ml}$ heparin, $100 \mathrm{U} / \mathrm{ml}$ penicillin, and $100 \mu \mathrm{g} / \mathrm{ml}$ streptomycin (17). Human umbilical vein endothelial cells were isolated and cultured as previously described (29). Human iliac artery endothelial cells, kindly provided by Dr. Peter Libby (Brigham \& Women's Hospital), were cultured in Medium 199 with 5\% FBS, 50 $\mu \mathrm{g} / \mathrm{ml}$ endothelial cell growth supplement, and $100 \mu \mathrm{g} / \mathrm{ml}$ heparin. All endothelial cells were used for experiments at passage levels $1-3$. The human monocyte-like cell lines, THP-1 and U937, were obtained from the American Type Culture Collection (Rockville, MD) and cultured in RPMI 1640 with 10\% FBS. Monocytes were isolated from freshly drawn human blood by ficoll-hypaque separation and centrifugal elutriation, as previously described (17).

Fluorescence immunoassay. Lyso-PC or related phospholipids were dissolved in ethanol ( $10 \mathrm{mM}$ stock solution), and added to Medium 199 with 5\% FBS at the final concentrations indicated immediately before incubation with confluent endothelial monolayers. In preliminary experiments, ethanol carrier alone tested at the highest final concentration was without effect. Lyso-PC analogues in chloroform solution were dried, suspended in Medium 199 by brief sonication and then 5\% FBS was added. After incubation with test stimuli, monolayers were washed with RPMI-1\% FBS and incubated on ice for $1 \mathrm{~h}$ with saturating concentrations of monoclonal antibodies (mAbs) directed to rabbit or human endothelial-leukocyte adhesion molecules. Subsequently, monolayers were washed three times with phosphate-buffered saline (PBS) containing $10 \%$ FBS and then incubated for $1 \mathrm{~h}$ on ice with a saturating concentration $(14 \mu \mathrm{g} / \mathrm{ml})$ of FITC-labeled $\mathrm{F}\left(\mathrm{ab}^{\prime}\right)_{2}$ fragments of anti-mouse IgG. After washing four times with PBS- $10 \%$ FBS, monolayers were lysed with a $0.01 \%$ (wt/vol) $\mathrm{NaOH}, 0.1 \%$ SDS buffer, and the fluorescence determined using a Pandex reader (Travenol Laboratories, Mundelein, IL). The mAbs Rbl/9 ( IgG $_{1}$; antirabbit VCAM-1), E1/6 ( IgG $_{1}$; anti-human VCAM-1 ), Hu 5/3 (IgG anti-human ICAM-1) and $\mathrm{H} 18 / 7\left(\mathrm{IgG}_{2 \mathrm{a}}\right.$; anti-human ELAM-1) were used to detect the surface expression of adhesion molecules $(15,17$, 29-31). The mAb Rb2/3 ( $\operatorname{IgG}_{1}$ ) putatively recognizes rabbit ICAM-1, an inducible $92-96 \mathrm{kD}$ polypeptide up-regulated in LPS-treated rabbit endothelium (17). Specific cell surface binding in this assay was calculated by subtracting the fluorescence detected in monolayers incubated with a class-matched nonbinding primary $\mathrm{mAb}$. A stimulation index for immunobinding was calculated as the ratio of specific cell surface $\mathrm{mAb}$ binding to monolayers treated with lyso-PC or other test stimuli, versus monolayers treated with medium alone.

Northern blot analysis. Total cellular RNA extracted from cultured rabbit aortic or human umbilical vein endothelial cells by acid-guanidinium phenol-chloroform method (32) was electrophoresed through $1 \%$ agarose gels containing formaldehyde, and transferred to nitrocellulose membranes (Schleicher \& Schuell, Inc., Keene, NH). Northern blots were hybridized with rabbit VCAM-1 or human ICAM-1 cDNA probes labeled by $\left[\alpha{ }^{32} \mathrm{P}\right] \mathrm{dCTP}$ (Amersham Corp., Arlington Heights, IL) using random hexanucleotide primers (Pharmacia, Inc., Piscataway, NJ) (33). A 2.1-kb Hind III/Pst I fragment of rabbit VCAM-1 cDNA or a 1.3-kb Xho I fragment of human ICAM-1 cDNA was utilized. The ICAM-1 cDNA was provided by Dr. Brian Seed (Massachusetts General Hospital, Boston, MA) (10). The blots were rehybridized with radiolabeled rat brain $\alpha$-tubulin cDNA.

Leukocyte adhesion assays. Leukocyte adhesion assays were performed in microtiter plates as previously described (17, 29). After incubated with test stimuli or media alone, endothelial monolayers were washed three times with RPMI $16401 \%$ FBS. BCECF-labeled leukocytes $\left(2 \times 10^{5}\right.$ cells in $200 \mu$ l of RPMI $16401 \%$ FBS $/ 32-\mathrm{mm}^{2}$ well $)$ were added, and microtiter plates were incubated for $10 \mathrm{~min}$ at $37^{\circ} \mathrm{C}$. The plates were sealed, inverted, and centrifuged $(250 \mathrm{~g})$ for $5 \mathrm{~min}$ to separate nonadherent leukocytes. Adherent cells were lysed with 50 $\mathrm{mM}$ Tris, $\mathrm{pH} 8.4,0.1 \%$ SDS, and their fluorescence was measured. A stimulation index for leukocyte adhesion was calculated as the ratio of the number of leukocytes associated with lyso-PC- or LPS-treated versus sham-treated endothelial monolayers.

Statistical analysis. The statistical significance of the differences among means of groups was determined using Student's two-sample $t$ test or analysis of variance.

\section{Results}

Lyso-PC up-regulates expression of VCAM-1 and ICAM-1 in rabbit aortic endothelial cells. Cultured rabbit aortic endothelial cell monolayers were treated with lyso-PC in Medium 199 containing 5\% FBS, and cell surface expression of VCAM-1 was measured by fluorescence immunobinding assays using $\mathrm{Rb} 1$ /9, a mAb specific for rabbit VCAM-1. Lyso-PC treatment up-regulated the cell surface expression of VCAM- 1 in a doseand time-dependent fashion. In response to $100 \mu \mathrm{M}$ lyso-PC, VCAM-1 was significantly induced above baseline at $4 \mathrm{~h}$, and continued to increase in a sustained fashion for at least $36 \mathrm{~h}$ (Fig. $1 A$ ). Concentrations of lyso-PC as low as $50 \mu \mathrm{M}$ suspended in 5\% FBS caused a significant increase in VCAM-1 expression detected at $24 \mathrm{~h}$ of treatment, with a maximal effect observed at $100 \mu \mathrm{M}$ (Fig. $1 \mathrm{~B}$ ). As seen in Table I, after $24 \mathrm{~h}$ of treatment, the extent of VCAM-1 induction by lyso-PC was variable among experiments (3-24-fold increases); however, in a given experiment, the stimulation obtained with lyso-PC was comparable (60-146\%) to that obtained with a maximally effective concentration of Gram-negative bacterial endotoxin (LPS, $1 \mu \mathrm{g} / \mathrm{ml}$ ). Cell surface expression of ICAM-1, as detected by $\mathrm{mAb} \mathrm{Rb} 2 / 3$, also was increased by lyso-PC treatment by 1.4-6.2-fold (38-108\% of maximal LPS stimulation). In contrast, a constitutively expressed antigen on the surface of rabbit endothelium recognized by $\mathrm{mAb} \mathrm{Rb} 2 / 13\left(\mathrm{IgG}_{1}\right)$ was not significantly affected by lyso-PC treatment (Table I).

Northern blot analysis demonstrated that increased cell surface expression of VCAM-1 on rabbit aortic endothelium 

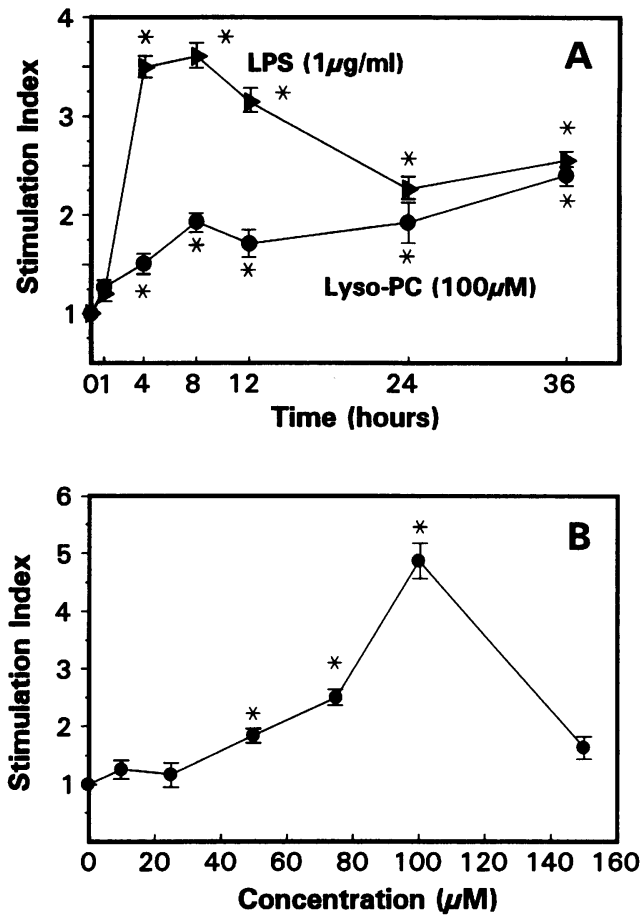

Figure 1. VCAM-1 induction by lyso-PC or LPS in rabbit aortic endothelial cells. $(A)$ Time course: endothelial monolayers were treated with lyso-PC $(100 \mu \mathrm{M}, \bullet)$ or LPS $(1 \mu \mathrm{g} / \mathrm{ml}, \bullet)$ in Medium 199 with $5 \%$ FBS for the indicated times, and cell surface expression of VCAM-1 measured by fluorescence immunoassay. $(B)$ Dose response: endothelial monolayers were treated with the indicated concentrations of lyso-PC in Medium 199 with 5\% FBS for $24 \mathrm{~h}$, and cell surface expression of VCAM-1 was measured by fluorescence immunoassay. Stimulation index ( \pm SEM, $n=3$ ) was calculated as described in Methods. ${ }^{*} P<0.05$ vs. control, one of two representative experiments.

was correlated with a significant increase in VCAM-1 mRNA (Fig. 2). Two predominant species of rabbit VCAM-1 mRNA were found, consistent with alternative mRNA splicing (34) or differential polyadenylation.

Lyso-PC pretreatment of rabbit aortic endothelial cells increases adhesion of blood monocytes and monocyte-like cell lines. To determine if increased cell surface expression of leukocyte adhesion molecules induced by lyso-PC correlated with a hyperadhesive endothelial phenotype, leukocyte adhesion assays were performed with human monocyte-like cell lines, THP-1 and U937. Lyso-PC pretreatment of rabbit aortic endothelial monolayers resulted in increased adhesion of each of these leukocytes, 1.6-3.5-fold for THP-1 cells, and 1.4-2.0-fold for U937 cells ( Table II). Adhesion of elutriated human blood monocytes to lyso-PC-treated rabbit aortic endothelial cells also was enhanced by 1.4 -fold $(P<0.01$, one experiment $)$ under similar assay conditions. Addition of lyso-PC immediately preceding the leukocyte adhesion assay, followed by the standard washing procedure, did not increase monocyte adhesion (data not shown).

Lyso-PC differentially induces ELAM in human arterial and venous endothelial cells. We further characterized the effect of lyso-PC on cultured human endothelial cells. We found that lyso-PC induced cell surface expression of both VCAM-1 and ICAM-1 in human iliac arterial cells, in a comparable fash-
Table I. Lyso-PC Induces Cell Surface Expression of VCAM-1 and ICAM-1 in Rabbit Aortic Endothelial Celis

\begin{tabular}{cccc}
\hline & \multicolumn{3}{c}{ Immunobinding stimulation index (\% LPS maximum) } \\
\cline { 2 - 4 } Expt. & VCAM-1 & ICAM-1 & Rb2/13 antigen \\
\hline 1 & $23.8 \pm 2.02(145)^{\S}$ & $6.2 \pm 0.68(108)^{\S}$ & $\mathrm{ND}$ \\
2 & $3.4 \pm 0.19(98)^{\S}$ & $1.4 \pm 0.08(78)^{*}$ & $1.02 \pm 0.03$ \\
3 & $4.9 \pm 0.38(64)^{\S}$ & $2.8 \pm 0.22(51)^{\S}$ & $1.09 \pm 0.02$ \\
4 & $2.5 \pm 0.26(60)^{\S}$ & $1.8 \pm 0.09(38)^{\ddagger}$ & $1.07 \pm 0.02$ \\
5 & $3.0 \pm 0.11(135)^{\ddagger}$ & ND & ND \\
\hline
\end{tabular}

Confluent monolayers of rabbit aortic endothelial cells were pretreated with lyso-PC $(100 \mu \mathrm{M})$ in the presence of $5 \%$ FBS for $24 \mathrm{~h}$, and cell surface expression of VCAM-1 and ICAM-1 measured by fluorescence immunobinding assays, as described in Methods. A constitutively expressed antigen recognized by a mAb Rb2/13 also was measured. Stimulation indices for each antigen were calculated as described in Methods. Percent LPS maximum (mean value) relates the stimulation index of lyso-PC treated cells to that observed with a maximally stimulatory concentration of LPS $(1 \mu \mathrm{g} / \mathrm{ml})$. Stimulation indices are expressed as mean $\pm \mathrm{SEM} ; n=3$ determinations in each experiment. Abbreviation: ND, not determined. ${ }^{*} P<0.05,{ }^{\ddagger} P$ $<0.01,{ }^{\S} P<0.005$.

ion to that observed with rabbit aortic endothelial cells ( Fig. 3). In contrast, in human umbilical vein endothelial cells, lyso-PC only induced ICAM-1 expression (Fig. 3). This up-regulation of ICAM-1 was much slower than that elicited by IL-1 (Fig. 4), and appeared similar to the pattern of VCAM-1 induction by lyso-PC observed in rabbit aortic endothelial cells, as shown in Fig. 1. The effect of lyso-PC on E-selectin (ELAM-1) expression was negligible at time points examined up to $24 \mathrm{~h}$ in both human iliac artery and umbilical vein endothelial cells (data not shown). Northern blot analysis showed a time-dependent increase in the amount of ICAM-1 mRNA in lyso-PC-treated human umbilical vein endothelial cells, which was detected as early as $4 \mathrm{~h}$ and remained sustained for at least $24 \mathrm{~h}$ (Fig. 5), whereas changes were not detected in VCAM-1 or E-selectin mRNA levels in human umbilical vein endothelial cells at any time point examined (data not shown). These results demonstrate that lyso-PC can selectively up-regulate VCAM-1 and ICAM-1, ELAM relevant to monocyte adhesion, in arterial endothelial cells. Interestingly, this expression pattern is distinctly different from that elicited by bacterial endotoxin or inflammatory cytokines such as IL-1 and tumor necrosis fac-

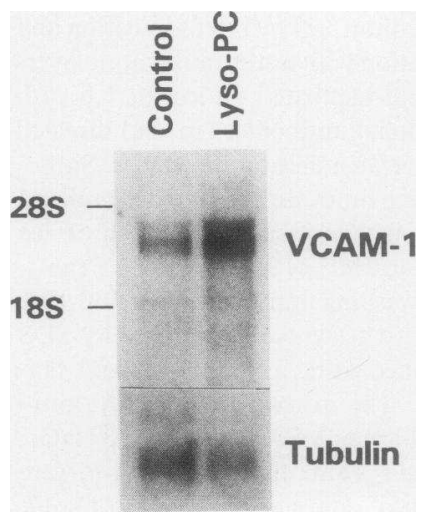

Figure 2. Northern blot analysis of VCAM-1 mRNA content in unstimulated and lyso-PC stimulated rabbit aortic endothelial cells. Endothelial monolayers were incubated for $6 \mathrm{~h}$ with or without lyso-PC $(100 \mu \mathrm{M})$ in Medium 199 with $5 \%$ FBS, and total cellular RNA was isolated and Northern blot analysis was performed, as described in Methods. Each lane contained 10 $\mu \mathrm{g}$ of total RNA. 
Table II. Lyso-PC Pretreatment of Rabbit Aortic Endothelial Cells Results in Enhanced Adhesion of Monocyte-like Cell Lines THP-1 and U937

\begin{tabular}{cccc} 
& & \multicolumn{2}{c}{$\begin{array}{c}\text { Adhesion stimulation index } \\
\text { (\% LPS maximum) }\end{array}$} \\
\cline { 3 - 4 } Expt. & $\begin{array}{c}\text { Lyso-PC } \\
\text { pretreatment }\end{array}$ & THP-1 & U937 \\
\hline 1 & $50 \mu \mathrm{M}, 8 \mathrm{~h}$ & $1.7 \pm 0.02(97)^{\S}$ & $2.0 \pm 0.08(83)^{\S}$ \\
2 & $100 \mu \mathrm{M}, 24 \mathrm{~h}$ & $3.5 \pm 0.06(97)^{\ddagger}$ & $\mathrm{ND}$ \\
3 & $100 \mu \mathrm{M}, 24 \mathrm{~h}$ & $1.6 \pm 0.10(91)^{\ddagger}$ & $1.4 \pm 0.10(89)^{*}$
\end{tabular}

Confluent monolayers of rabbit aortic endothelial cells were pretreated with lyso-PC in the presence of 5\% FBS. After washing monolayers with media without lyso-PC, leukocyte adhesion assays were performed and stimulation indices calculated, as described in Methods. Percent LPS maximum (mean value) was calculated as described in Table I. Stimulation indices are expressed as mean \pm SEM; $n=3-5$ determinations in each experiment. Abbreviation: ND, not determined. ${ }^{*} P<0.05,{ }^{\ddagger} P<0.02,{ }^{\S} P<0.002$.

tor, which characteristically induce E-selectin, VCAM-1, and ICAM-1 coordinately in all types of endothelial cells $(12,14-$ 16, 29, 31).

Effects of other polar phospholipids on the induction of $V C A M-1$ and ICAM-1. Lyso-PC is a polar phospholipid which can exhibit detergent-like properties. Generally, in an aqueous solution, such amphiphiles can cause cell lysis above their critical micellar concentrations. Previous studies have shown that critical micellar concentration of lyso-PC $(\mathrm{C} 16: 0)$ is $40-50 \mu \mathrm{M}$ in protein-free physiological salt solutions (35). In fact, we observed that $50 \mu \mathrm{M}$ or higher concentrations of lyso-PC in serum-free culture media caused morphologically apparent endothelial cell damage within a few hours. Because lyso-PC avidly binds to proteins such as albumin, we included 5\% FBS in the culture media and thereby increased its actual critical micellar concentration. With this incubation medium, we did not detect any cytotoxicity, as evidenced by phase-contrast microscopy or lactate dehydrogenase release, at lyso-PC concentrations up to $100 \mu \mathrm{M}$.
The effects of other lysophospholipids structurally similar to lyso-PC were examined, although such lysophospholipids typically are far less abundant in the body. As shown in Table III, when tested on both VCAM-1 induction in rabbit aortic endothelial cells and ICAM-1 induction in human umbilical vein endothelial cells at comparable concentrations, lysophosphatidylethanolamine was as effective as lyso-PC, while lysophosphatidylinositol and lysophosphatidylserine appeared less effective, and phosphatidylcholine was not active. The structural specificity of lyso-PC effect was further characterized in human umbilical vein endothelial cells, using hydrolyzable and nonhydrolyzable analogues of lyso-PC (36). As seen in Table IV, 1-palmityl-propanediol-3-phosphocholine, a nonhydrolyzable analogue, did not up-regulate ICAM-1 and actually caused cytotoxicity. In contrast, 1-palmitoyl-ethanediol-2phosphocholine, a hydrolyzable analogue, induced ICAM-1 expression in a dose-dependent fashion without evidence of cytotoxicity. Taken together, these observations suggest that the induction of endothelial-leukocyte adhesion molecules by lyso-PC or other lysophospholipids is separable from their detergent-like actions and may depend upon their active metabolism by endothelial cells.

\section{Discussion}

Adhesion of blood monocytes to the arterial endothelial surface, preceding their subsequent transmigration into the intima, is one of the key steps in atherogenesis (1-6). Once present within the developing lesion, monocyte/macrophages (as well as lymphocytes that also accumulate) have the capacity to produce various cytokines which, in turn, can activate endothelial cells locally to express adhesion molecules. Although such potential paracrine mechanisms for amplifying leukocyte recruitment are becoming better defined (37), the stimuli responsible for the initial monocyte recruitment into the arterial intima have not yet been identified. One of the earliest changes during atherogenesis, in cholesterol-fed animal models, is the focal accumulation of LDL in regions of the arterial wall, which subsequently develop foam cell lesions (38). Furthermore, several lines of evidence have indicated that oxidative

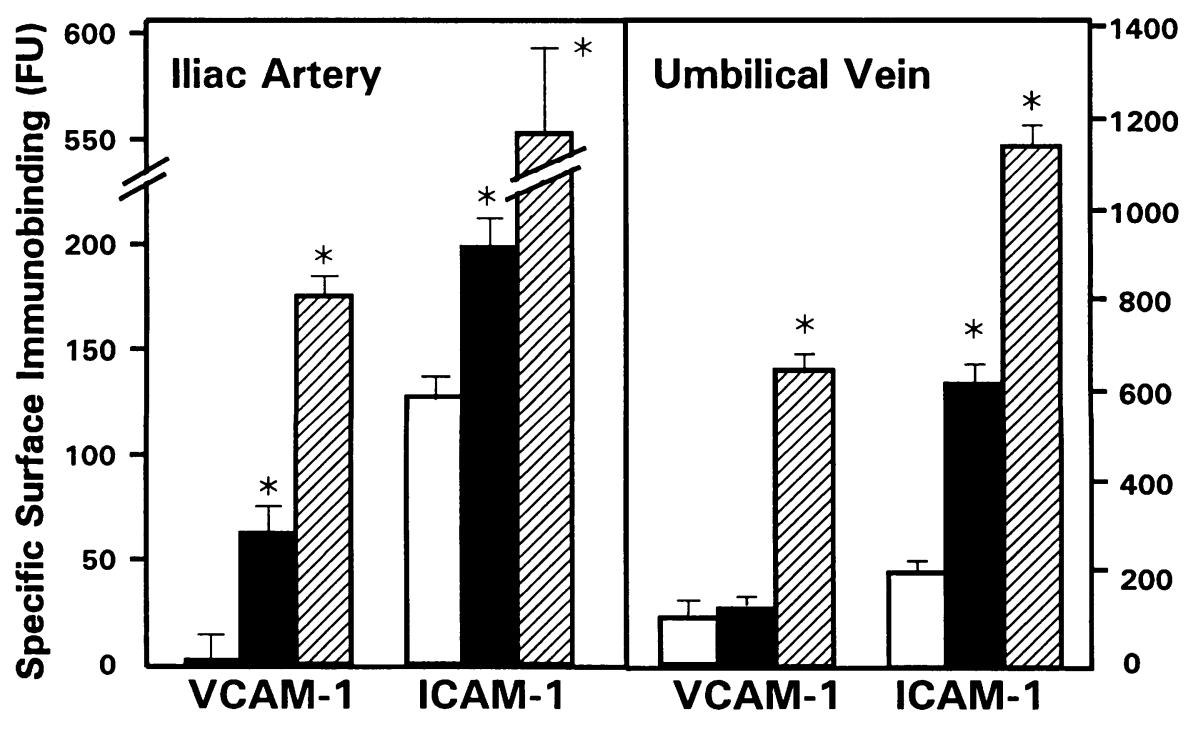

Figure 3. Patterns of cytokine and Lyso-PC induction of VCAM-1 and ICAM-1 in cultured human endothelial cells from iliac artery (left panel) and umbilical vein (right panel). Endothelial monolayers were treated with lyso-PC ( $100 \mu \mathrm{M}$, solid bars) or IL-1 ( $10 \mathrm{U} / \mathrm{ml}$, hatched bars $)$ in Medium 199 with 5\% FBS for $24 \mathrm{~h}$, and cell surface expression of VCAM- 1 and ICAM1 measured by fluorescence immunoassay as described in Methods. Sham-treated monolayers served as controls (open bars). Data are expressed as mean fluorescence units \pm SEM per well $(n=3) .{ }^{*} P<0.05$ vs. control, one of three representative experiments. 


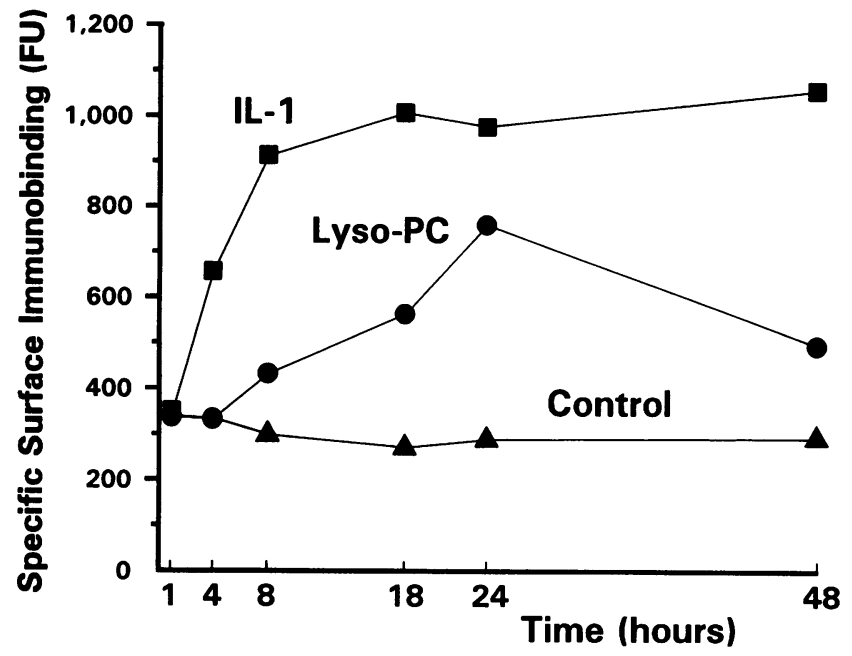

Figure 4. Kinetics of ICAM-1 induction by lyso-PC and IL-1 in cultured human umbilical vein endothelial cells. Endothelial monolayers were incubated with lyso-PC $(100 \mu \mathrm{M}, \bullet)$ or IL-1 $(10 \mathrm{U} / \mathrm{ml}$, -) in Medium 199 with 5\% FBS for the indicated times, and cell surface expression of ICAM-1 measured by fluorescence immunoassay, as described in Methods. Sham-treated monolayers served as controls (ム). Data are expressed as mean fluorescence units per well $(n=3$; one of two representative experiments).

modification of LDL can occur in arterial intima and may play a crucial role in atherogenesis $(3,20-23)$. Therefore, it is reasonable to hypothesize that oxidatively modified LDL, or one of its components, might be a initial stimulus for monocyte recruitment in this disease setting.

Recent in vitro studies have shown that cultured endothelial cells incubated with minimally oxidized LDL or $\beta$-VLDL exhibit enhanced adhesiveness for monocytes $(39,40)$ as well as the production of monocyte chemoattractant (9); however, neither component(s) of these lipoproteins responsible for these effects, nor their molecular mechanisms, have been fully clarified. As an initial approach to this problem, we isolated human plasma LDL and subjected it to various degrees of controlled oxidation, using cupric (41) or ferrous ions (39) in vitro, and then examined whether these modified lipoprotein preparations could activate cultured endothelial cells to enhance monocyte adhesion mechanisms. None of these oxidized LDL preparations (which contained 1-10 nmol malon-

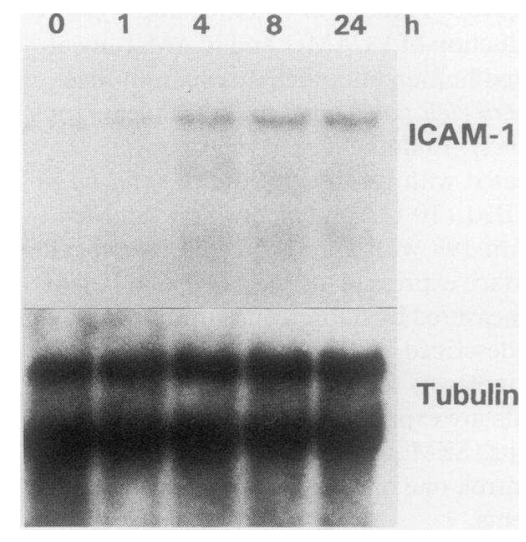

Figure 5. Northern blot analysis of ICAM- 1 in cultured human umbilical vein endothelial cells treated with lyso-PC. Cells were treated with lyso-PC ( $100 \mu \mathrm{M}$ with $5 \%$ FBS) for the indicated times and then total cellular RNA was isolated for Northern blot analysis as described in Methods.

Each lane contained 20 $\mu \mathrm{g}$ of total RNA.
Table III. Effect of Various Lysophospholipids on the Upregulation of VCAM-1 in Rabbit Aortic Endothelial Cells and ICAM-1 in Human Umbilical Vein Endothelial Cells

\begin{tabular}{lcc}
\hline & \multicolumn{2}{c}{ Immunobinding stimulation index } \\
\cline { 2 - 3 } \multicolumn{1}{c}{ Stimulant } & $\begin{array}{c}\text { VCAM-1 } \\
\text { (rabbit aorta) }\end{array}$ & $\begin{array}{c}\text { ICAM-1 } \\
\text { (human umbilical vein) }\end{array}$ \\
\hline Lyso-PC & $3.0 \pm 0.11$ & $2.1 \pm 0.10$ \\
Lysophosphatidylethanolamine & $3.4 \pm 0.05$ & $2.1 \pm 0.09$ \\
Lysophosphatidylinositol & $1.4 \pm 0.01$ & $1.8 \pm 0.09$ \\
Lysophosphatidylserine & $1.5 \pm 0.20$ & $1.4 \pm 0.07$ \\
Phosphatidylcholine & $1.1 \pm 0.16$ & $\mathrm{ND}$ \\
& & \\
\hline
\end{tabular}

Confluent monolayers of rabbit aortic endothelial cells were pretreated with the indicated phospholipids $(100 \mu \mathrm{M})$ for $24 \mathrm{~h}$ in the presence of 5\% FBS, fluorescence immunobinding assays were performed, and stimulation indices were calculated as described in Methods. Data are expressed as mean $\pm \mathrm{SEM} ; n=3$ determinations, one experiment (VCAM-1); $n=6$ determinations, two experiments (ICAM-1). Abbreviation: ND, not determined.

dialdehyde-equivalents of lipid peroxides per mg protein by a standard thiobarbituric acid-reactive substance assay), induced VCAM-1, ICAM-1, or E-selectin expression, in cultured rabbit aortic or human umbilical vein endothelial cells $(\mathrm{N}$. Kume, unpublished observations). However, as suggested by recent studies (42), the biological properties of oxidized LDL might vary among laboratories and different preparations, in that thiobarbituric acid-reactive substance, which is the usual measure of the extent of oxidative modification of LDL, does not adequately reflect all the relevant features of the modified lipoprotein particle. We, therefore, considered the possibility that something associated with oxidized LDL preparations might be involved. As we demonstrate here, lyso-PC, a polar phospholipid that is increased in oxidized $\operatorname{LDL}(3,20,24,26$, 27 ) can up-regulate the expression of endothelial-leukocyte ad-

Table IV. Effect of Hydrolyzable and Nonhydrolyzable Analogues of Lyso-PC on ICAM-1 Expression in Human Umbilical Vein Endothelial Cells

\begin{tabular}{cccc}
\hline $\begin{array}{c}\text { Concentration } \\
\text { tested }\end{array}$ & $\begin{array}{c}\text { Lyso-PC } \\
\text { (palmitoyl) }\end{array}$ & $\begin{array}{c}\text { 1-Palmityl-propanediol } \\
\text {-3-phosphocholine }\end{array}$ & $\begin{array}{c}\text { 1-Palmitoyl-ethanediol- } \\
\text {-2-phosphocholine }\end{array}$ \\
\hline$\mu M$ & & & \\
25 & ND & $1.06 \pm 0.22$ & $1.05 \pm 0.14$ \\
50 & ND & $<1$ & $1.30 \pm 0.12$ \\
75 & $5.4 \pm 0.33^{*}$ & $<1$ & $2.22 \pm 0.21^{*}$ \\
100 & ND & $<1$ & $3.64 \pm 0.04^{*}$ \\
125 & ND & $<1$ & $5.12 \pm 0.24^{*}$ \\
& & & \\
\hline
\end{tabular}

Confluent monolayers of human umbilical vein endothelial cells were incubated with the indicated amounts of lyso-PC or related analogues for $24 \mathrm{~h}$ in the presence of 5\% FBS, cell surface expression of ICAM-1 was measured, and stimulation indices were calculated, as described in Methods. Data are expressed as mean \pm SEM. Note: Stimulation index, $<1$ was correlated with visible cytotoxicity. Abbreviation: ND, not determined. ${ }^{*} P<0.05$ vs. control, $n=3$ determinations. 
hesion molecules relevant to mononuclear leukocyte adhesion. Because lyso-PC bound to free cholesterol may not easily transfer onto cell membranes differences in the amounts of free cholesterol in LDL particles might affect the amount of transferable lyso-PC in an in vitro culture system. In addition, because lyso-PC is a polar phospholipid, and can be liberated into aqueous solution during the procedures of oxidative modification or long-term storage, some oxidized LDL preparations may contain significant amounts of lyso-PC dissociated from LDL particles. These possibilities may explain the lack of effect of our oxidized LDL preparations, per se, on endothelial-monocyte adhesion mechanisms. However, in contrast to the in vitro cell culture setting, oxidized LDL generated in the arterial intima in vivo $(3,20,23)$ may form in intimate contact with endothelial membranes, thus enhancing the possibility of transfer of lyso-PC into the endothelial cells. Conversely, the relatively large amount of lyso-PC associated with lipoproteins or albumin in circulating plasma may not be readily transferable to endothelial membranes.

The potential molecular mechanisms of endothelial activation by polar phospholipids such as lyso-PC appear to be multiple and complex. Taken together, our results with hydrolyzable and nonhydrolyzable analogues of lyso-PC suggest that specific molecular transformations rather than non-specific (e.g., detergent-like) actions are involved. Previous studies with human monocytes (36) and a lymphoblastic cell line (43) have implicated the generation of diacylglycerol, via a metabolic pathway involving (lyso) phospholipase $\mathrm{C}$, in the chemotactic action of exogenous lyso-PC. Diacylglycerol, an important intracellular second messenger and activator of protein kinase $C(44)$, could conceivably also be generated from lyso-PC in endothelial cells through the sequential action of a phosphatidylcholine-hydrolyzing phospholipase D activity and phosphatidate phosphatase. Both protein kinase C-dependent and -independent mechanisms have been described in the induction of adhesion molecules (E-selectin, ICAM-1, and VCAM-1) by the inflammatory cytokine TNF, in vascular endothelial cells (45-47). Our preliminary studies with the protein kinase $\mathrm{C}$ inhibitor, staurosporine, failed to show any consistent inhibition of lysoPC-induced ICAM-1 expression in human umbilical vein endothelial cells. Given the striking differences in the pattern of endothelial adhesion molecule induction by lyso-PC compared with well-characterized activators such as IL-1, TNF, and LPS, further studies of VCAM-1 and ICAM-1 induction by lyso-PC might be expected to provide new information regarding the molecular mechanisms of endothelial activation.

The present study demonstrates that lyso-PC can activate endothelial cells to differentially express certain adhesion molecules in vitro, and suggests that this naturally occurring phospholipid may be an important stimulus for mononuclear leukocyte recruitment into the arterial intima during atherogenesis, in vivo. In this respect, it may function either alone or in combination with inflammatory cytokines generated locally by activated vessel wall cells and emigrating leukocytes (37). Interestingly, preliminary data have recently been presented that lyso-PC also can act on monocyte/macrophages to up-regulate growth factor gene expression (48), thus further illustrating its potential role in atherogenesis. In addition to its presence in atherogenic lipoproteins, such as oxidatively modified LDL and $\beta$-VLDL, biologically significant amounts of lyso-PC can also be generated via the action of phospholipase $A_{2}$ secreted by leukocytes, platelets, and other cells in inflammatory tissues (49). Thus, lyso-PC may contribute to acute and chronic inflammation through both its previously described direct chemoattractant actions (24) and the up-regulation of relevant endothelial adhesion mechanisms. Interventions which prevent the conversion of phosphatidylcholine into lyso-PC in vivo would be predicted to act to reduce the recruitment of mononuclear leukocytes in various pathophysiologic settings. Further studies of the mechanisms responsible for the local generation and cellular actions of lyso-PC may provide fresh insights into the atherosclerotic disease process.

\section{Acknowledgments}

The authors thank Dr. Peter Libby ( Vascular Medicine and Atherosclerosis Unit, Cardiovascular Division, Brigham and Women's Hospital, Boston, MA) for providing cultured human iliac artery endothelial cells, and W. Atkinson and $\mathrm{K}$. Case for assistance in cell culture. We also gratefully acknowledge Dr. Sampath Parthasarathy (Division of Endocrinology and Metabolism, Department of Medicine, University of California at San Diego, La Jolla, CA) for his generous gift of lysoPC analogues and helpful discussions.

This research was supported by grants from the National Institutes of Health (PO1-HL-36028 and RO1-HL-45563). Noriaki Kume currently is a recipient of a postdoctoral research fellowship award from the Massachusetts Affiliate of the American Heart Association, and has been supported, in part, by an Overseas Fellowship from Toyobo Biotechnology Foundation (Tokyo, Japan).

\section{References}

1. Ross, R. 1986. The pathogenesis of atherosclerosis-An update. N. Engl. J. Med. 314:488-500.

2. Munro, J. M., and R. S. Cotran. 1988. The pathogenesis of atherosclerosis: Atherosclerosis and inflammation. Lab. Invest. 58:249-261.

3. Steinberg, D., S. Parthasarathy, T. E. Carew, J. C. Khoo, and J. L. Witztum. 1989. Beyond cholesterol: modifications of low-density lipoproteins that increase its atherogenicity. N. Engl. J. Med. 320:915-924.

4. Gerrity, R. G., H. K. Naito, M. Richardson, and C. J. Schwartz. 1979. Dietary induced atherogenesis in swine. Am. J. Pathol. 95:775-785.

5. Joris, T., J. J. Nunnari, F. J. Krolikowski, and G. Majno. 1983. Studies on the pathogenesis of atherosclerosis. I. Adhesion and emigration of mononuclear cells in the aorta of hypercholesterolemic rats. Am. J. Pathol. 113:341-358.

6. Faggiotto, A., R. Ross, and L. Harker. 1984. Studies of hypercholesterolemia in the nonhuman primates. I. Changes that lead to fatty streak formation. Arteriosclerosis. 4:323-340.

7. Ylä-Herttuala, S., B. A. Lipton, M. E. Rosenfeld, T. Sarkioja, T. Yoshimura, E. J. Leonard, J. L. Witztum, and D. Steinberg. 1991. Expression of monocyte chemoattractant protein 1 in macrophage-rich area of human and rabbit atherosclerotic lesions. Proc. Natl. Acad. Sci. USA. 88:5252-5256.

8. Nelken, N. A., S. R. Coughlin, D. Gordon, and J. N. Wilcox. 1991. Monocyte chemoattractant protein-1 in human atherosclerotic plaques. J. Clin. Invest. 88:1121-1127

9. Cushing, S. D., J. A. Berliner, A. J. Valente, M. Navab, F. Parhami, R. Gerrity, C. J. Schwartz, and A. M. Fogelman. 1990. Minimally modified low density lipoprotein induces monocyte chemotactic protein 1 in human endothelial cells and smooth muscle cells. Proc. Natl. Acad. Sci. USA. 87:5134-5138.

10. Simmons, D., M. W. Makgoba, and B. Seed. 1988. ICAM. An adhesion ligand of LFA-1 is homologous to the neural cell adhesion molecule NCAM. Nature (Lond.). 331:624-627.

11. Staunton, D. E., S. D. Marlin, C. Stratowa, M. L. Dustin, and T. A. Springer. 1988. Primary structure of ICAM-1 demonstrates interaction between members of immunoglobulin and integrin supergene families. Cell. 52:925-933.

12. Bevilacqua, M. P., S. Stengelin, M. A. Gimbrone, Jr., and B. Seed. 1989. Endothelial leukocyte adhesion molecule 1: an inducible adhesion receptor to neutrophils related to complement regulatory proteins and lectins. Science (Wash. DC). 243:1160-1165.

13. Bevilacqua, M., E. Butcher, B. Furie, M. Gallatin, M. Gimbrone, J. Harlan, K. Kishimoto, L. Lasky, R. McEver, J. Paulson, et al. 1991. Selectins: a family of adhesion receptors. Cell. 67:233.

14. Osborn, L., C. Hession, R. Tizard, C. Vassalio, S. Luhowsky, G. ChiRosso, and R. Lobb. 1989. Direct expression cloning of vascular cell adhesion 
molecule 1 . A cytokine-induced endothelial protein that bind lymphocytes. Cell. 59:1203-1211.

15. Rice, G. E., J. M. Munro, and M. P. Bevilacqua. 1990. Inducible cell adhesion molecule 110 (INCAM-110) is an endothelial receptor for lymphocytes: a CD11/CD18-independent adhesion mechanisms. J. Exp. Med. 171:1369-1374.

16. Carlos, T., N. Kovach, B. Schwartz, M. Rosa, B. Newman, E. Wayner, C. Benjamin, L. Osborn, R. Lobb, and J. Harlan. 1991. Human monocyte bind to two cytokine-induced adhesion ligands on cultured human endothelial cells: Endothelial-leukocyte adhesion molecule- 1 and vascular cell adhesion molecule-1. Blood. 77:2266-2271.

17. Cybulsky, M. I., and M. A. Gimbrone, Jr. 1991. Endothelial expression of a mononuclear leukocyte adhesion molecule during atherogenesis. Science (Wash. DC). 251:788-791.

18. Li, H., M. I. Cybulsky, M. A. Gimbrone, Jr., and P. Libby. 1991. Early induction of an atherosclerosis-associated endothelial-leukocyte molecule (Athero-ELAM) by an atherogenic diet in rabbits. Arterioscler. Thromb. 11:1397a (Abstr.)

19. Poston, R. N., D. O. Haskard, J. R. Coucher, N. P. Gall, and R. R. Johnson-Tiedy. 1992. Expression of intercellular adhesion molecule-1 in atherosclerotic plaques. Am. J. Pathol. 140:665-673.

20. Witztum, J. L., and D. Steinberg. 1991. Role of oxidized low density lipoprotein in atherogenesis. J. Clin. Invest. 88:1785-1792.

21. Kita, T., Y. Nagano, M. Yokode, K. Ishii, N. Kume, A. Ooshima, H. Yoshida, and C. Kawai. 1987. Probucol prevents the progression of atherosclerosis in Watanabe heritable hyperlipidemic rabbit, an animal model for familial hypercholesterolemia. Proc. Natl. Acad. Sci. USA. 84:5928-5931.

22. Carew, T. E., D. C. Schwenke, and D. Steinberg. 1987. Antiatherogenic effect of probucol unrelated to its hypocholesterolemic effect: evidence that antioxidant in vivo can selectively inhibit low density lipoprotein degradation in macrophage-rich fatty streaks slowing the progression of atherosclerosis in the WHHL rabbit. Proc. Natl. Acad. Sci. USA. 84:7725-7729.

23. Palinski, W., M. E. Rosenfeld, S. Ylä-Herttuala, G. C. Gurtner, S. S. Socher, S. W. Butler, S. Parthasarathy, T. E. Carew, D. Steinberg, and J. L. Witztum. 1989. Low density lipoprotein undergoes oxidative modification in vivo. Proc. Natl. Acad. Sci. USA. 86:1372-1380.

24. Quinn, M. T., S. Parthasarathy, and D. Steinberg. 1988. Lysophosphatidylcholine: a chemotactic factor for human monocytes and its potential role in atherogenesis. Proc. Natl. Acad. Sci. USA. 85:2805-2809.

25. Parthasarathy, S., M. T. Quinn, D. C. Schwenke, T. E. Carew, and D. Steinberg. 1989. Oxidative modification of beta-very low density lipoprotein. Potential role in monocyte recruitment and foam cell formation. Arteriosclerosis. 9:398-404.

26. Kugiyama, K., S. A. Kerns, J. D. Morrisett, R. Roberts, and P. Henry. 1990. Impairment of endothelial-dependent arterial relaxation by lysolecithin in modified low-density lipoproteins. Nature (Lond.). 344:160-162.

27. Yokoyama, M., K. Hirata, R. Miyake, H. Akita, Y. Ishikawa, H. Fukuzaki. 1990. Lysophosphatidylcholine: essential role in the inhibition of endothelial-dependent vasorelaxation by oxidized low density lipoprotein. Biochem. Biophys. Res. Commun. 16:301-308.

28. Portman, O. W., and M. Alexander. 1969. Lysophosphatidylcholine concentration and metabolism in aortic intima plus inner media: effect of nutritionally induced atherosclerosis. J. Lipid Res. 10:158-165.

29. Luscinskas, F. W., A. F. Brock, A. Arnaout, and M. A. Gimbrone, Jr. 1989. Endothelial-leukocyte adhesion molecule-1-dependent and leukocyte (CD11/CD18)-dependent mechanisms contribute to polymorphonuclear leukocyte adhesion to cytokine-activated human vascular endothelium. J. Immunol. 142:2257-2263.

30. Luscinskas, F. W., M. I. Cybulsky, J. M. Kiely, C. S. Peckins, V. M. Davis, and M. A. Gimbrone, Jr. 1991. Cytokine-activated human endothelial monolayers support enhanced neutrophil transmigration via a mechanism involving both endothelial-leukocyte adhesion molecule-1 and intercellular adhesion molecule-1. J. Immunol. 146:1617-1625.
31. Rice, G. E., and M. P. Bevilacqua. 1989. An inducible endothelial cell surface glycoprotein mediates melanoma adhesion. Science (Wash. DC). 246:1303-1306.

32. Chomczynski, P., and N. Sacchi. 1987. Single-step method of RNA isolation by acid guanidinium thiocyanate-phenol-chloroform extraction. Anal. Biochem. 162:156-159.

33. Sambrook, J., E. Fritsch, and T. Maniatis. 1989. Molecular Cloning, a Laboratory Manual. 2nd edition. Cold Spring Harbor Laboratories, Cold Spring Harbor, NY.

34. Cybulsky, M. I., J. W. U. Fries, A. J. Williams, P. Sultan, V. M. Davies, M. A. Gimbrone, Jr., and T. Collins. 1991. Alternative splicing of human VCAM-1 in activated vascular endothelium. Am. J. Pathol. 138:815-820.

35. Bergmann, S. R., T. B. Ferguson, Jr., and B. E. Sobel. 1981. Effects of amphiphiles on erythrocytes, coronary arteries and perfused hearts. Am. J. Physiol. $\mathrm{H} 229-\mathrm{H} 237$.

36. Quinn, M. T., N. Kondratenko, and S. Parthasarathy. 1991. Analysis of the monocyte chemotactic response to lysophosphatidylcholine: role of lysophospholipase C. Biochim. Biophys. Acta. 1082:293-302.

37. Libby, P., and G. K. Hansson. 1991. Involvement of the immune system in human atherosclerosis: current knowledge and unanswered questions. Lab. Invest. 64:5-15.

38. Schwenke, D. C., and T. E. Carew. 1989. Initiation of atherosclerotic lesions in cholesterol-fed rabbits. I. Focal increases in arterial LDL concentration precede development of fatty streak lesions. Arteriosclerosis. 9:895-907.

39. Berliner, J. A., M. C. Territo, A. Sevanian, S. Ramin, J. A. Kim, B. Bamshad, M. Esterson, and A. M. Fogelman. 1990. Minimally modified low density lipoprotein stimulates monocyte endothelial interactions. J. Clin. Invest. 85:1260-1266.

40. Territo, M. C., J. A. Berliner, L. Almada, R. Ramirez, and A. M. Fogelman. 1989. $\beta$-VLDL pretreatment of endothelial monolayers increases monocyte but not neutrophil adhesion. Arteriosclerosis. 9:824-828.

41. Kume, N., H. Arai, C. Kawai, and T. Kita. 1991. Receptors for modified low-density lipoproteins in human endothelial cells: different recognition for acetylated low-density lipoprotein and oxidized low-density lipoprotein. Biochim. Biophys. Acta. 1091:63-67.

42. Clinton, S. K., R. Underwood, L. Hayes, M. L. Sherman, D. W. Kufe, and P. Libby. 1992. Macrophage colony-stimulating factor gene expression in vascular cells and in experimental and human atherosclerosis. Am. J. Pathol. 140:301316.

43. Nishijima, J., T. M. Wright, R. D. Hofman, F. Liao, D. E. Symer, and H. S. Shin. 1989. Lysophosphatidylcholine metabolism to 1,2-diacylglycerol in lymphoblasts: involvement of a phosphatidylcholine-hydrolyzing phospholipase C. Biochemistry. 28:2902-2909.

44. Nishizuka, Y. 1988. Molecular heterogeneity of protein kinase $\mathrm{C}$ and its implications for cellular regulation. Nature (Lond.). 334:661-665.

45. Ritchie, A. J., D. R. Johnson, B. M. Ewenstein, and J. S. Pober. 1991. Tumor necrosis factor induction of endothelial cell surface antigen is independent of protein kinase $C$ activation or inactivation: studies with phorbol myristate acetate and staurosporine. J. Immunol. 146:3056-3062.

46. Montgomery, K. F., L. Osborn, C. Hession, R. Tizard, D. Goff, C. Vassalo, P. I. Tarr, K. Bomsztyk, R. Lobb, J. M. Harlan, and T. H. Pohlman. 1991. Activation of endothelial-leukocyte adhesion molecule 1 (ELAM-1) gene transcription. Proc. Natl. Acad. Sci. USA. 88:6523-6527.

47. Deisher, T. A., T. L. Haddix, K. F. Montgomery, T. H. Pohlman, and J. M. Harlan. 1991. Differential regulation of ELAM-1 and VCAM-1 expression in human umbilical vein endothelial cells by protein kinase C. Circulation. 84:II404. (Abstr.)

48. Nakano, T., E. W. Raines, J. A. Abraham, M. Klagsbrun, and R. Ross. 1992. Lysophosphatidylcholine induces monocyte expression of heparin-binding EGF-like growth factor mRNA. J. Cell. Biochem. Suppl. 16A:18. (Abstr.)

49. Vadas, P., and W. Pruzanski. 1986. Role of secretory phospholipase $A_{2}$ in the pathobiology of disease. Lab. Invest. 55:391-404. 